University of Montana

ScholarWorks at University of Montana

Graduate Student Theses, Dissertations, \&

Professional Papers

Graduate School

2012

BRUCELLOSIS TRANSMISSION BETWEEN WILDLIFE AND

LIVESTOCK IN THE GREATER YELLOWSTONE ECOSYSTEM:

INFERENCES FROM DNA GENOTYPING

Michael Patrick O'Brien

The University of Montana

Follow this and additional works at: https://scholarworks.umt.edu/etd

Let us know how access to this document benefits you.

Recommended Citation

O'Brien, Michael Patrick, "BRUCELLOSIS TRANSMISSION BETWEEN WILDLIFE AND LIVESTOCK IN THE

GREATER YELLOWSTONE ECOSYSTEM: INFERENCES FROM DNA GENOTYPING" (2012). Graduate

Student Theses, Dissertations, \& Professional Papers. 161.

https://scholarworks.umt.edu/etd/161

This Professional Paper is brought to you for free and open access by the Graduate School at ScholarWorks at University of Montana. It has been accepted for inclusion in Graduate Student Theses, Dissertations, \& Professional Papers by an authorized administrator of ScholarWorks at University of Montana. For more information, please contact scholarworks@mso.umt.edu. 


\title{
BRUCELLOSIS TRANSMISSION BETWEEN WILDLIFE AND LIVESTOCK IN THE GREATER YELLOWSTONE ECOSYSTEM: INFERENCES FROM DNA GENOTYPING
}

\author{
by \\ MICHAEL P. O'BRIEN \\ Presented in partial fulfillment of the requirements \\ For the degree of \\ Master of Science \\ Professional Paper, Non-thesis Option \\ in the Wildlife Biology Program \\ University of Montana \\ Missoula, MT \\ April 2012 \\ Approved by: \\ Gordon Luikart, Co-Chair \\ Flathead Lake Biological Station \\ Fred W. Allendorf, Co-Chair \\ Division of Biological Sciences \\ L. Scott Mills \\ Wildlife Biology Program
}


I. Preface

II. Manuscript for Publication............................................... 5

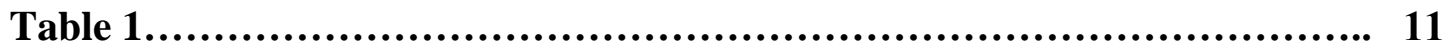

Figure 1.................................................................. 12

III. Appendix.............................................................. 14

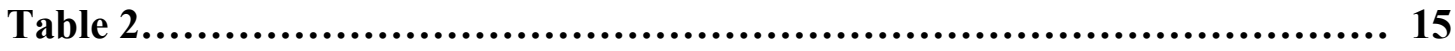

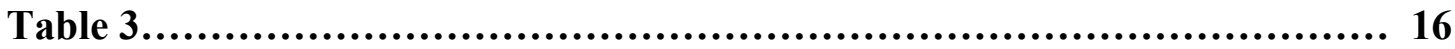

Figure 2 ............................................................................. 17

Figure 3................................................................... 19 


\section{$\underline{\text { I. Preface }}$}

The purpose of this preface is to introduce my professional paper entitled "Brucellosis Transmission among Wildlife and Livestock in the Greater Yellowstone Ecosystem: Inferences from DNA Genotyping", which is submitted in partial fulfillment of my programmatic requirements towards the Masters of Science degree in Wildlife Biology. This preface provides a brief summary of my educational and career goals and to explain how my graduate project has contributed significantly toward my ability to achieve those goals. Following the preface is the professional paper, which is formatted (without subheadings) as required for submission to the Journal of Wildlife Diseases as a Short Communication. Appended after the professional paper is an Appendix describing additional data not used in my professional paper, along with knowledge I gained from the collaborative production and analyses of those data.

In 2009, I began my graduate school experience with a clear understanding that I wanted a career in the biological sciences - specifically, Wildlife Biology. However, like many graduate students, I thought when I initiated graduate school that my graduate work would yield a profound set of results, which could change the face of the field. And, like many new graduate students, in my pursuit to "save the world", I did not understand the amount of time, money and other resources that are required to produce even a modest dataset. With a tempered perspective at the close of my first year in graduate school, I learned that developing a graduate project is more about developing a single solid, novel research question, and about employing the appropriate techniques to test a hypothesis (or set of hypotheses) related to that question. I also learned that it is important to develop a research question that can be adequately addressed given the money, resources, and time at one's disposal.

As my project began to take shape, it also became apparent that developing and maintaining productive collaborations with other faculty and students is often critical to the success of a project. With collaborators and an extremely helpful support team, I was able to develop and complete a modest but significant study on Brucella genetics in wild and domestic ungulates (elk, bison, and cattle). Specifically, we started by screening Brucella isolates using Affymetrix microarrays (hybridization chips) with the aim of elucidating sources of Brucella infection in cattle of the Greater Yellowstone Ecosystem (GYE). The system, ultimately, was not simple and straightforward (see Appendix). There were no quick or clear answers. The microarray data did not resolve any significant genomic differences between isolates obtained from bison and/or bison. Therefore, we obtained data from VNTRs. It is at this point that the project began to take shape.

My professional paper describes the analysis and interpretation of Brucella genetic data (VNTRs) in the context of hypothesized transmission routes among populations of elk, bison, and cattle in the GYE. Although the dataset could eventually be expanded and additional geographic regions and time points to yield a more complete story, we have demonstrated the usefulness of these types of genetic data. Furthermore, we are able to suggest potential transmission routes between elk, bison, and cattle that are informative and likely useful for wildlife managers and livestock growers. It is the opinion of my 
collaborators and mentors that the work accomplished is sufficient and adequate for publication in a peer-reviewed scientific journal, and will be submitted for publication to a journal in Fall of 2012. Thus, although there are more questions to be answered and a need to expand the dataset, I submit this professional paper and seek to move forward along my career trajectory.

With respect to my career, upon completion of my Master's degree, I will seek employment as a research associate or field scientist with a federal agency or academic research group. Several job options have emerged including an opportunity to work on an international research project genotyping cattle to test for inbreeding (and perhaps disease susceptibility) and to screen for common bovine pathogens in small herds maintained by Indigenous communities in the Sierra Tarahumara in Mexico. My Master's work has provided me with the fundamental skills required to engage in this type of work. Specifically, my Master's education provided me with knowledge to conduct scientific research and skills to use powerful molecular techniques, computational analyses, and to apply them to investigate pathogen transmission. I also have gained expertise and comfort working in the field with large ungulates and livestock.

In closing this Preface, I would like to again thank my collaborators, friends, and family for their support and assistance during the course of my graduate studies. I genuinely hope that all will enjoy the following professional paper.

\section{Acknowledgements}

I am extremely grateful to the following people: Gordon Luikart for his intellectual guidance and patience as I progressed through aspects of my training; Fred Allendorf and Scott Mills for their guidance and patience serving on my committee; Rick Wallen (Yellowston National Park) for his advice, support, and providing numerous bison samples and Brucella abortus bacteria isolates from YNP; the biologists at NVSL (National Veterinary Services Laboratories) for all their support and of course the wonderful VNTR (variable number of tandem repeats, i.e., microsatellite) data set; Neil Anderson and Julie Cunningham (Montana Fish Wildlife and Parks) for helping provide elk isolates from Montana elk; Hank Edwards (Wyoming Game and Fish) for his advice and providing the Wyoming elk isolates; Albano Beja-Pereira for his support and advice while I analyzed my data and for allowing me to do so in his lab (CIBIO) in the University of Porto, Portugal; and Michael Ceballos for all his support, encouragement, advice, and the numerous hours he aided me during the writing process. Without these collaborators, colleagues, and friends, I could not have completed my Master's project. 


\title{
II. Manuscript for Publication
}

\section{Brucellosis Transmission between Wildlife and Livestock in the Greater Yellowstone Ecosystem: Inferences from DNA Genotyping}

Michael P. O’Brien ${ }^{1,2,9}$, Albano Beja-Pereira ${ }^{2}$, Neil Anderson ${ }^{3}$, Ruben M. Ceballos ${ }^{4,5}$, Hank Edwards ${ }^{6}$, James Higgins ${ }^{7}$, Beth Harris ${ }^{7}$ and Gordon Luikart ${ }^{2,8}$

${ }^{1}$ Fish and Wildlife Genomics Group, Division of Biological Sciences, University of Montana, 32 Campus Drive, BRB011, Missoula, MT 59812, USA

${ }^{2}$ Centro de Investigacao em Biodiversidade e Recursos Geneticos (CIBIO-UP), Universidade do Porto, Rua Padre Armando Quintas, 4485-661 Vairão (VCD), Portugal

${ }^{3}$ Montana Fish, Wildlife and Parks, 1400 South 19th Ave, Bozeman, MT 59718, USA

${ }^{4}$ Native American Research Laboratory, Division of Biological Sciences, University of Montana, 32 Campus Drive, HS104, Missoula, MT 59812, USA

${ }^{5}$ Biology Department, University of Minnesota-Morris, Science 2310, 600 East Fourth Street, Morris, MN 56267, USA

${ }^{6}$ Wyoming Game and Fish Wildlife Forensics and Fish Health Laboratory, Biosciences Bldg., Room 32, Department 3312, 1000 E. University Ave., Laramie, WY 82071, USA

${ }^{7}$ USDA/APHIS/NVSL, Mycobacteria and Brucella Section, 1920 Dayton Ave., Ames, IA 50010, USA

8 Flathead Lake Biological Station, Division of Biological Sciences, University of Montana, 32125 Bio Station Lane, Polson, MT 59860, USA

${ }^{9}$ Corresponding author (email: michael2.obrien@umontana.edu)

\begin{abstract}
Brucellosis transmission between wildlife species and cattle in the greater Yellowstone ecosystem has been difficult to assess because the causative agent Brucella abortus bacteria is extremely difficult to isolate for DNA genotyping. We examined transmission of $B$. abortus between bison, elk, and cattle using nine variable-number tandem repeat (VNTR) markers on DNA from 98 isolates of $B$. abortus recovered from elk, bison, and cattle. All specimens were from geographically distinct populations in Idaho, Montana, and Wyoming. A haplotype network consisting of 54 individual haplogroups was generated from these isolates using Network v4.61. Network assessments of genetic relatedness among Brucella isolates showed that genotypes from the 2008 cattle outbreak in Wyoming matched elk B. abortus genotypes, confirming elk as the likely source. Network assessments showed substantial interspecific transmission between elk and bison populations in Montana. The $B$. abortus from the two recent outbreaks $(2007,2008)$ in Montana cattle had genotypes similar to isolates from both bison and elk. Because wild bison have been excluded from the Montana cattle areas for decades as part of wildlife management policy, our findings suggest transmission likely occurred between bison and elk in Yellowstone before eventually being transmitted to cattle in southern Montana. Finally, the occurrence of identical B. abortus genotypes between individual Montana elk suggests that brucellosis might have recently become established in Montana, either by
\end{abstract}


transmission from northern Yellowstone bison or from infected elk immigrants from Wyoming.

Key words: Bos bison, Bos taurus, Brucella abortus, brucellosis, cattle, Cervus elaphus, elk, infectious disease outbreak

One of the most common bacterial zoonoses worldwide is brucellosis (Godfroid, 2002). Brucellosis is caused by an intracellular bacterium Brucella abortus that is notoriously difficult to isolate and study. Brucellosis infects reproductive organs leading to reproductive failure such as aborted pregnancies in both wild and domesticated ungulates (Cheville et al. 1998).

In the United States, brucellosis in the Greater Yellowstone Ecosystem (GYE) is a concern following outbreaks in cattle during the past two and a half decades in Wyoming, Montana, and Idaho. Brucellosis is now prevalent in wild populations of bison (Bos bison) and elk (Cervis elaphus) in the GYE after being introduced to North America with cattle and this subsequently led to infections in other wildlife species residing in the area (Meagher and Meyer 1994, Olsen, 2010). Several other wildlife species in the GYE have been identified as potential hosts due to spillover from bison and elk; these other species include such as grizzly bears (Ursus arctos), moose (Alces alces), bighorn sheep (Ovis canadensis), and mule deer (Odocoileus hemionus); however, these species are not believed to maintain or contribute to the spread of B. abortus (Cheville et al. 1998). Until recently, elk were thought to be an insignificant vector of brucellosis transmission to cattle in the GYE (McCorquodale \& DiGiacomo 1985, Cheville et al. 1998). The transmission of brucellosis from wildlife to cattle previously resulted in large economic losses to producers from slaughtering whole herds when a few infected animals were detected, in addition to increased disease testing requirements and decreased marketability of their cattle (Kilpatrick et al. 2009, USDA-APHIS 2011).

Beja-Pereira et al. (2009) suggested that brucellosis outbreaks in cattle in Idaho and Wyoming (in 2002 and 2003, respectively) originated from elk because B. abortus DNA profiles from elk isolates were nearly identical (i.e., within one mutational step) to $B$. abortus isolated from cattle. The Beja-Pereira et al. study was based on nine "variable number tandem repeat" sequences (VNTRs), which are used by the National Animal Disease Center for B. abortus strain discrimination.

More recently, brucellosis outbreaks in cattle have occurred in Montana (2007, 2008) and Wyoming (2008). To assess the wildlife species of origin for these B. abortus outbreaks, we used a VNTR-9 assay employed by the National Veterinary Services Laboratories (NVSL) in Ames, Iowa (Higgins et al. 2012). This new set of loci includes some of the same VNTRs used in previous work (Beja-Pereira et al., 2009) along with several new markers that have been shown to be more variable and provide higher resolution for discrimination between strains of B. abortus (Whatmore et al. 2006). We analyzed 98 isolates primarily collected from 2007-2010 across a larger geographic area within the GYE than reported in Beja-Pereira et al. (Table 1). 
Elk isolates were collected from hunter-killed individuals or during management removals of infected individuals. Isolates from Yellowstone bison were collected from individuals captured at the boundary of the park during winter migrations to prevent comingling with cattle in Montana. The lone bison isolate from the Jackson herd was collected at the National Elk Refuge in 2009 during hunting season. Cattle isolates were obtained from infected livestock herds during documented brucellosis outbreaks in 2002 (Idaho), 2007 (Montana), and 2008 (Montana and Wyoming).

VTNR genotypes for 98 isolates were obtained from NVSL. A subset of these isolates $(n=78)$ were cultured and identified as $B$. abortus by NVSL while the remaining isolates were processed and identified by Wyoming Game and Fish $(n=20)$. DNA from all cultured isolates was extracted using a DNEasy Blood and Tissue Kit (Qiagen, CA, USA) using standard manufacturer's protocols. Samples were then genotyped using a set of nine VNTRs (Table 2), which were selected due to their high degree of genetic variability and their ability to discriminate between strains within the genus $B$. abortus (Bricker \& Ewalt 2005; Whatmore et al. 2006).

Genetic relationships or VNTR allelic profiles were analyzed using NETWORK v4.61 (Fluxus Technology Ltd. 2004-2012) to construct a haplotype network. NETWORK can be used to infer genetic relatedness among individual isolates by generating a type of phylogenetic tree known as a "haplotype network." NETWORK identifies the number of mutational steps that separate a given set of haplotypes and accounts for haplotype frequency at a given node. As described in Almendra et al. (2009) and Beja-Pereira et al. (2009), our analyses were conducted using a pre-processing star contraction before conducting a median-joining algorithm in order to reduce the overall complexity of the haplotype network. A maximum parsimony (MP) post calculation was also performed in order to delete all non-MP links, or more specifically, links not included in the most parsimonious or "shortest" trees in the network.

Our clustering analysis generated a network of 54 haplotypes of B. abortus. Nodes (indicated by filled circles) represent $B$. abortus 9-locus VNTR genotypes (Figure 1). Size in the filled circles is proportional to the number of host individuals with that specific 9locus $B$. abortus genotype. Several of the nodes in the resulting network consist of isolates obtained from both elk and bison with identical VNTR profiles or haplotypes consistent with the hypothesis of inter-specific transmission.

In addition, VNTR profiles of isolates from the Wyoming cattle outbreaks of 2008 group closely with, or are identical to isolates obtained from elk. Cattle are strictly monitored and any $B$. abortus seropositive animals are culled. Consideration of this management policy in context with the results from our phylogenetic network analysis suggest that elk are the source of the outbreaks in 2008 since haplotypes of $B$. abortus identified are genetically distinct from bison. This conclusion is concordant with results from Beja-Pereira et al. (2009), which also suggests that elk were the source of earlier cattle outbreaks in Wyoming and Idaho in 2002 and 2003. 
Since $B$. abortus samples from the two Montana cattle outbreaks are genetically similar to isolates obtained from both elk and bison in Montana, the data cannot resolve the wildlife source species of cattle infections in Montana. However, Yellowstone bison have been precluded by humans from entering far into the Paradise Valley of Montana for more than 100 years (White et al. 2011). Also, northern Yellowstone elk do not migrate as far north in the Paradise Valley where these cattle outbreaks occurred (White et al. 2010). Thus, this finding emphasizes interspecies transmission between bison, elk and cattle in in the northern portion of GYE and suggests elk in the Paradise Valley are currently a maintenance host for Brucella and a transmission vector to cattle.

Results from this haplotype network analysis contradict results presented in BejaPereria et al. (2009), which suggested little to no interspecific transmission between elk and bison in the GYE. One plausible explanation for this discrepancy is that sampling in the previous study was limited to a smaller geographic area and a smaller sample size of isolates with few samples from the northern region of the GYE. This underscores the importance of larger sample size and broader geographic coverage in formulating reliable conclusions about disease transmission.

The clustering of Montana elk isolates (Figure 1) may be indicative of intraspecific transmission between elk away from the Wyoming feed grounds. These data support results from modeling analyses conducted by Cross et al. (2009), which suggested that the migration of elk from the Wyoming feed grounds alone cannot explain the current rise in B. abortus prevalence observed in Montana elk. Our results indicate that several Montana elk possess $B$. abortus isolates with identical genotypes indicating a recent transmission event. However, neither the modeling nor the empirical data presented here can differentiate between vertical (mother-to-calf) and horizontal (between unrelated individuals) transmission. Since each node only represents a pair of isolates, a larger sample size would help to decrease the probability of mother-to-calf sample bias and resolve whether intraspecific transmission is actually occurring away from feed grounds and whether current management strategies are sufficient to control the spread of brucellosis.

In summary, a phylogenetic analysis based on nine informative VNTR loci for Brucella isolates collected from bison, elk and cattle in the GYE support the hypothesis that there is interspecific transmission of brucellosis between elk, bison and cattle, and intraspecific transmission among elk within populations (in Montana) far away from the Wyoming feed grounds. It also suggests that elk were the source of transmission causing the Wyoming cattle brucellosis outbreaks of 2008. The analysis suggests transmission likely occurred between Yellowstone bison and northern GYE elk in the past, before eventually being transmitted among elk and by elk to cattle in Montana.

We thank the National Park Service (especially P.J. White and Rick Wallen) and F. Gardipee and C. Almandra for their advice and help with sampling. Funding was provided by Centro de Investigacao em Biodivirsidade Recursos Geneticos Universidad do Porto (CIBIO), UP, University of Montana, and research grants from the Portuguese Science Foundation (PTDC/CVT/69438/2006, SFRH/BPD/26802/2006 and 
SFRH/BD30737/2006). M.O. was supported by the Sloan Foundation. G.L. was supported by grants from the Walton Family Foundation, the Portuguese Science Foundation (FCT) grant PTDC/BIA-BDE/65625/2006, and the U.S. National Science Foundation Grant DEB 1067613. FWA and GL were partially supported by U.S. National Science Foundation Grant DEB 074218. Helpful advice and comments were provided by L.S. Mills and three anonymous referees. The views and opinions in this article are those of the authors and should not be construed to represent any views, determinations, or policies of the federal agencies involved with this research.

\section{Literature Cited}

Almendra, C., T. L. Silva, A. Beja-Pereira, A.C. Ferreira, L. Ferraõ-Beck, M. Correa de Sa, B.J. Bricker, \& G. Luikart. 2009. 'HOOF-Print'” genotyping and haplotype inference discriminates among Brucella spp. isolates from a small spatial scale. Infect Genet Evol 9:104-107.

Archie, E.A., G. Luikart, \& V.O. Ezenwa. 2009. Infecting epidemiology with genetics: A new frontier in disease ecology. Trends Ecol Evol 24:21-31.

Beja-Pereira, A., B. Bricker, S. Chen, P.J. White, \& G. Luikart. 2009. DNA genotyping suggests that recent brucellosis outbreaks in the greater Yellowstone area originated from elk. J Wildl Dis 45:1174-1177.

Bricker, B., \& Ewalt, D.R. (2005) Evaluation of the HOOF-printing assay for typing Brucella abortus strains isolated from cattle in the United States: results with four performance criteria. BMC Microbiol 5:37-47.

Cheville, N., D. McCullough, \& L. Paulson. 1998. Brucellosis in the Greater Yellowstone Area. National Academy Press. Washington D. C.

Cross, P.C., E.K. Cole, A.P. Dobson W.H. Edwards, K.L. Hamlin, A.D. Middleton, B.M. Scurlock, P.J. White. 2010. Probable causes of increasing brucellosis in freeranging elk of the Greater Yellowstone Ecosystem. Ecol Appl 20:278-288.

Cook, A.R., W. Otten, G. Marlon, G.J. Gibson, \& C.A. Gill. 2007. Estimation of multiple transmission rates from epidemics in heterogeneous populations. Proc Natl Acad Sci USA 104:20392-20397.

Godfroid, J. 2002. Brucellosis in wildlife. OIE Scientific and Technical Review: Infectious diseases of wildlife: detection, diagnosis and management 21:277-286.

Higgins, J.A., T. Stuber, C. Quance, W.H. Edwards, R. V. Tiller, T. Linfield, J. Rhyan, A. Berte, \&B. Harris. 2012. Molecular epidemiology of Brucella abortus isolates from cattle, elk, and bison in the United States: 1998 - 2011. Appl Environ Microbiol 78:3674-3684.

Kilpatrick, A.M, C.M. Gillin, \& P. Daszak. 2009. Wildlife-livestock conflict: the risk of pathogen transmission from bison to cattle outside Yellowstone National Park. $J$ Appl Ecol 46:476-485.

Meagher, M. \& M. Meyer. 1994. On the origin of brucellosis in bison of Yellowstone National Park: A review. Conserv Biol 3:645-653.

McCorquodale, S.M. \& R.F.DiGiacomo. 1985. The role of wild North American ungulates in the epidemiology of bovine brucellosis: a review. J Wildl Dis 21:351357

Olsen, S.C. 2010. Brucellosis in the United States: role and significance of wildlife reservoirs. Vaccine 28:73-75. 
Tanaka, M.M., A.R. Francis, F. Luciani, \& S.A. Sisson. 2006. Using approximate bayesian computation to estimate tuberculosis transmission parameters from genotype data. Genetics 173:1511-1520.

USDA-APHIS. 2011. Brucellosis disease information. Retrieved from http://www.aphis.usda.gov/animal_health/animal_diseases/brucellosis/

Whatmore, A.M., S.J. Shankster, L.L. Perrett, T.J. Murphy, S.D. Brew, R.E. Thriwall, S.J. Cutler \& A.P. MacMillan. 2006. Identification and characterazation of variablenumber tandem-repeat markers for typing of Brucella spp. J Clin Mocrobiol 44:1982-1993.

White, P.J., K.M. Proffitt, L.D. Mech, S.B. Evans, J.A. Cunningham \& K.L. Hamlin. 2010. Migration of northern Yellowstone elk - implications of spatial structuring. $J$ Mammal 91:827-837.

White, P. J., R. L. Wallen, C. Geremia, J. J. Treanor, \& D. W. Blanton. 2011.

Management of Yellowstone bison and brucellosis transmission risk - Implications for conservation and restoration. Biol Conserv 144:1322-1334. 
Table 1. Host species, state, geographic origin, and year of sample collection for 98 Brucella abortus bacteria isolates VNTR genotyped in this study.

\begin{tabular}{|c|c|c|c|c|}
\hline Host & State & Geographic Origin & Year & No. of Brucella Isolates \\
\hline \multirow[t]{6}{*}{ Bison } & $\mathrm{MT}$ & Yellowstone National Park (YNP) * & 2002 & 2 \\
\hline & MT & YNP* & 2005 & 2 \\
\hline & MT & YNP* & 2008 & 1 \\
\hline & MT & YNP, Mammoth Hot Springs & 2008 & 3 \\
\hline & MT & YNP, Gardiner area & 2008 & 38 \\
\hline & WY & National Elk Refuge & 2009 & 1 \\
\hline \multirow[t]{4}{*}{ Cattle } & ID & Conant Creek & 2002 & 2 \\
\hline & $\mathrm{MT}$ & Bridger & 2007 & 1 \\
\hline & MT & Pray & 2008 & 1 \\
\hline & WY & Unknown & 2008 & 2 \\
\hline \multirow[t]{20}{*}{ Elk } & ID & Conant Creek & 2002 & 3 \\
\hline & MT & Madison County & 2005 & 1 \\
\hline & MT & Unknown & 2008 & 2 \\
\hline & MT & YNP, Gardiner area & 2009 & 7 \\
\hline & MT & YNP, Gardiner area & 2010 & 11 \\
\hline & WY & National Elk Refuge & 1999 & 1 \\
\hline & WY & Black Butte Feed Ground (FG) & 2000 & 1 \\
\hline & WY & Grand Teton National Park & 2001 & 1 \\
\hline & WY & Unknown & 2005 & 2 \\
\hline & WY & National Elk Refuge & 2006 & 1 \\
\hline & WY & Soda Lake FG & 2006 & 1 \\
\hline & WY & Franz FG & 2006 & 1 \\
\hline & WY & National Elk Refuge & 2007 & 1 \\
\hline & WY & Cody & 2007 & 1 \\
\hline & WY & South Park FG & 2008 & 1 \\
\hline & WY & Horse Creek FG & 2008 & 1 \\
\hline & WY & Grey's River FG & 2008 & 1 \\
\hline & WY & Dell Creek FG & 2009 & 2 \\
\hline & WY & Franz FG & 2009 & 4 \\
\hline & WY & Horse Creek FG & 2009 & 2 \\
\hline
\end{tabular}

*exact location unknown 


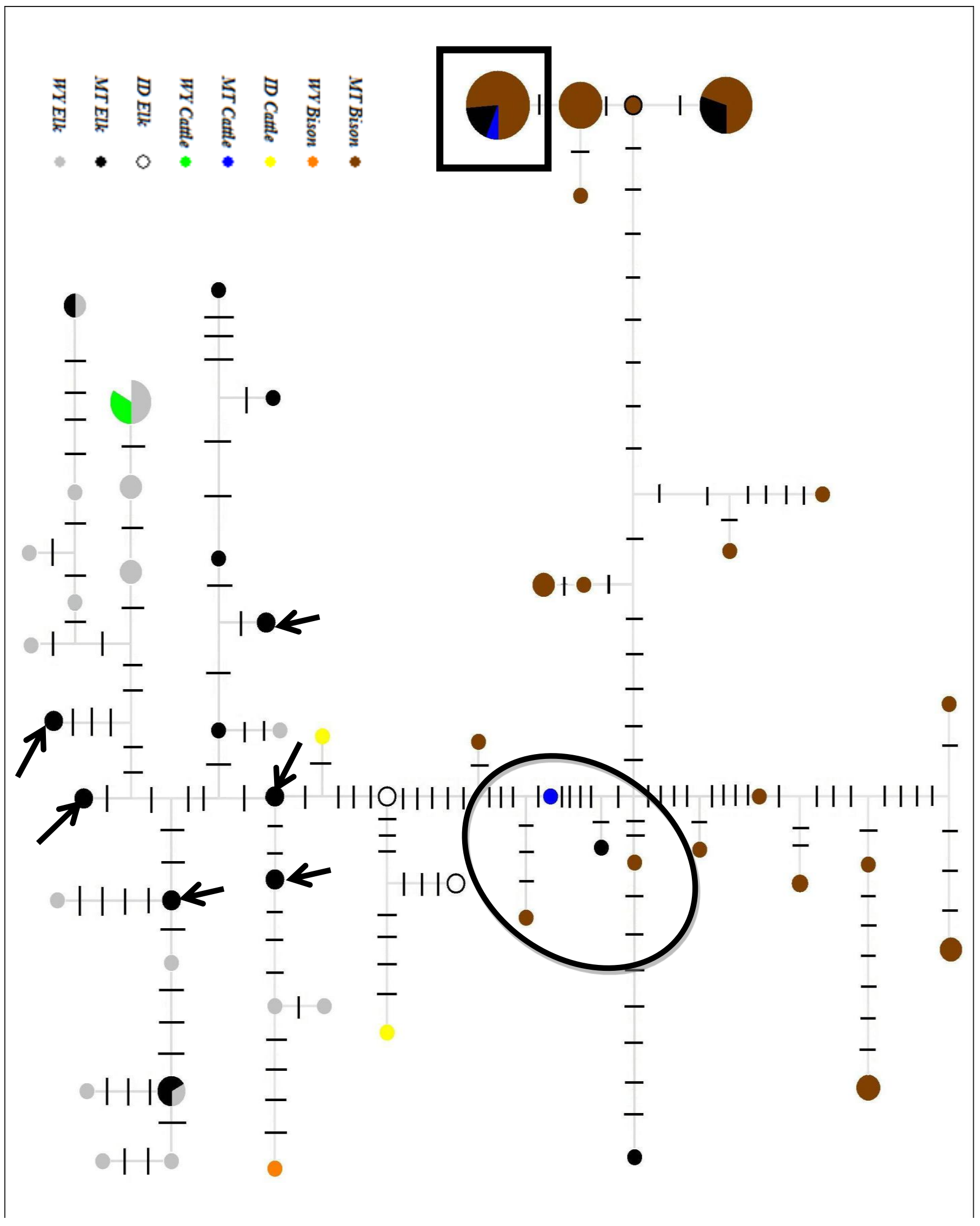


Figure 1. Haplotype network of 54 Brucella abortus haplogroups from 98 B. abortus isolates obtained from bison, cattle, and elk in the Greater Yellowstone Ecosystem (GYE). Haplotypes consist of unique multilocus genotypes from nine informative VNTR loci. The size of each filled circle (pie) is proportional to the frequency of that haplotype. Colors correspond to a host species from a given state (Montana, Wyoming or Idaho, see legend on bottom left). Each hash mark on a branch represents a minimum of one mutation step assuming a stepwise mutational model (and no recombination). The thick black square shows that a Montana cattle $B$. abortus isolate (blue, from 2007) has a haplotype identical to $B$. abortus from both bison (brown) and elk (black) from Montana. The thick black oval shows that the Montana B. abortus cattle isolate (blue, from 2008) has a haplotype differing by 4-5 mutations from both Montana bison (brown) and elk (black) isolates. The six black arrows show sets of two (Montana) elk that shared and identical haplotype, consistent with hypothesized transmission between those elk in Montana. 


\section{Appendix}

I report here briefly on additional data not used in my professional paper and on knowledge gained from a visit to and collaboration with the genomics team lead by Steven Porcella at the Rocky Mountain Laboratories (RML), National Institute of Allergy and Infectious Diseases, Hamilton, MT.

A subset of fifty-three of the VNTR-genotyped isolates (from my manuscript/paper) were also successfully genotyped at RML, using the custom Affymetrix GeneChip RMLchip2a520312F which is comprised of 1933 probe sets containing DNA sequences (oligonucleotide probes) from the Brucella melitensis, Brucella suis and Brucella abortus genomes. Within the array, each probe set consists of 11-20 probes that are 25 nucleotides in length with a variable nucleotide contained at the $13^{\text {th }}$ position on a probe and are spread out throughout an open reading frame (ORF). Results for a given ORF are presented as present or absent with and "absence reading" requiring a minimum of three of the probes within a given probe set (locus or ORF) to not hybridize to the array. The presence/absence call data obtained from the array data was then analyzed by RML using GeneSpring GX 7.3 to create a hierarchical clustering (tree) using a Pearson correlation similarity measure with average linkage to produce a dendrogram to illustrate relationships among isolates.

Out of the subset of isolates sent to RML, three isolates were identified as outliers during RML's analyses with one excluded entirely in the construction of the dendrogram. The dendogram lacked any clear pattern regarding source of infection to cattle in Idaho, Montana, and Wyoming due to the high degree of inferred genomic similarity among all the isolates. However, RML identified and constructed a gene list of 17 ORFs that they dubbed regions of interest due to the observed polymorphisms (gene segment presence/absence) and potential for single nucleotide polymorphisms (SNPs) within these regions. We used the presence/absence call data provided from these 17 gene polymorphisms and constructed a haplotype network using NETWORK v4.61. The results from this analysis mirrored the results of analysis conducted by RML suggesting that the microarray hybridization approach lacks the resolution to detect genomic differences to resolve among Brucella isolates obtained from bison, cattle, and elk in the GYE.

For these data to potentially become informative and publishable, we would need the results from probe-specific binding for each probe set within each ORF contained within the microarray. This would require additional analyses and resources for which RML could potentially provide in the future. Another option would be to sequence the 17 ORFs. This could provide data to resolve among isolates and help understand transmission patterns to guide management and surveillance of brucellosis in the Greater Yellowstone area. 
Table 2. Haplotype diversity for the variable number tandem repeat (VNTR) makers used in this investigation as well as the diversity for the same markers as reported in a global investigation of Brucella abortus (Whatmore et al 2006). Also included are the $95 \%$ confidence intervals for SDI, number of alleles observed at a given VNTR in this investigation $(\mathrm{K})$ and the frequency of the most common allele $(\max (\mathrm{pi}))$ observed in this investigation.

\begin{tabular}{|c|c|c|c|c|c|c|}
\hline Locus & Whatmore SDI & SDI $^{1}$ & CI Lower ${ }^{2}$ & CI Upper ${ }^{2}$ & $\mathbf{K}^{3}$ & $\max (p i)^{4}$ \\
\hline$H-1$ & 0.89 & 0.866 & 0.826 & 0.906 & 13 & 0.25 \\
\hline$H-3$ & 0.83 & 0.317 & 0.161 & 0.472 & 5 & 0.821 \\
\hline $\mathrm{H}-4$ & 0.79 & 0.865 & 0.825 & 0.904 & 11 & 0.25 \\
\hline$V-16$ & 0.74 & 0.163 & 0.04 & 0.285 & 2 & 0.911 \\
\hline$V-17$ & 0.39 & 0.035 & 0 & 0.102 & 2 & 0.982 \\
\hline$V-2$ & 0.63 & 0.666 & 0.594 & 0.738 & 6 & 0.411 \\
\hline$V-21$ & $n d$ & 0.035 & 0 & 0.102 & 2 & 0.982 \\
\hline$V-5 A$ & 0.75 & 0.576 & 0.456 & 0.696 & 4 & 0.607 \\
\hline$V-5 B$ & 0.82 & 0.875 & 0.849 & 0.901 & 10 & 0.196 \\
\hline
\end{tabular}

${ }^{1}$ Simpson Diversity Index (SDI) $=$ A measure of the variation of the number of repeats at each locus. Ranges from 0.0 (no diversity) to 1.0 (complete diversity)

${ }^{2}$ Confidence Interval $(\mathbf{C I})=$ Precision of the Diversity Index, expressed as 95\% upper \& lower boundaries

${ }^{3} \mathbf{K}=$ Number of different repeats present at this locus in this sample set

${ }^{4} \mathbf{m a x}(\mathbf{p i})=$ Fraction of samples that have the most frequent repeat number in this locus (range 0.0 to 1.0)

$\boldsymbol{n d}=$ No diversity 
Table 3. Host species, state, year of sample collection and sum totals states and species for the 98 Brucella abortus bacteria isolates VNTR genotyped in this study. (Simplified version of Table 1 and may be more suitable for publication.)

\section{Species}

\begin{tabular}{|c|c|c|c|c|c|}
\hline & Yea & Bison & Cattle & Elk & $\begin{array}{l}\text { Sum } \\
\text { totals }\end{array}$ \\
\hline aho & 2002 & 0 & 2 & 3 & 5 \\
\hline
\end{tabular}

\section{Montana (MT)}

\begin{tabular}{|l|r|r|r|}
\hline 2002 & 2 & 0 & 0 \\
\hline 2005 & 2 & 0 & 1 \\
\hline 2007 & 0 & 1 & 0 \\
\hline 2008 & 42 & 1 & 2 \\
\hline 2009 & 0 & 0 & 7 \\
\hline 2010 & 0 & 0 & 11 \\
6
\end{tabular}

Wyoming (WY)

\begin{tabular}{|l|l|l|l|}
\hline 1999 & 0 & 0 & 1 \\
\hline 2000 & 0 & 0 & 1 \\
\hline 2001 & 0 & 0 & 1 \\
\hline 2005 & 0 & 0 & 2 \\
\hline 2006 & 0 & 0 & 3 \\
\hline 2007 & 0 & 0 & 2 \\
\hline 2008 & 0 & 2 & 8 \\
\hline 2009 & 1 & 0 & 3 \\
\hline $\begin{array}{l}\text { Sum } \\
\text { totals }\end{array}$ & $\mathbf{4 7}$ & $\mathbf{6}$ & $\mathbf{4 5}$ \\
\end{tabular}




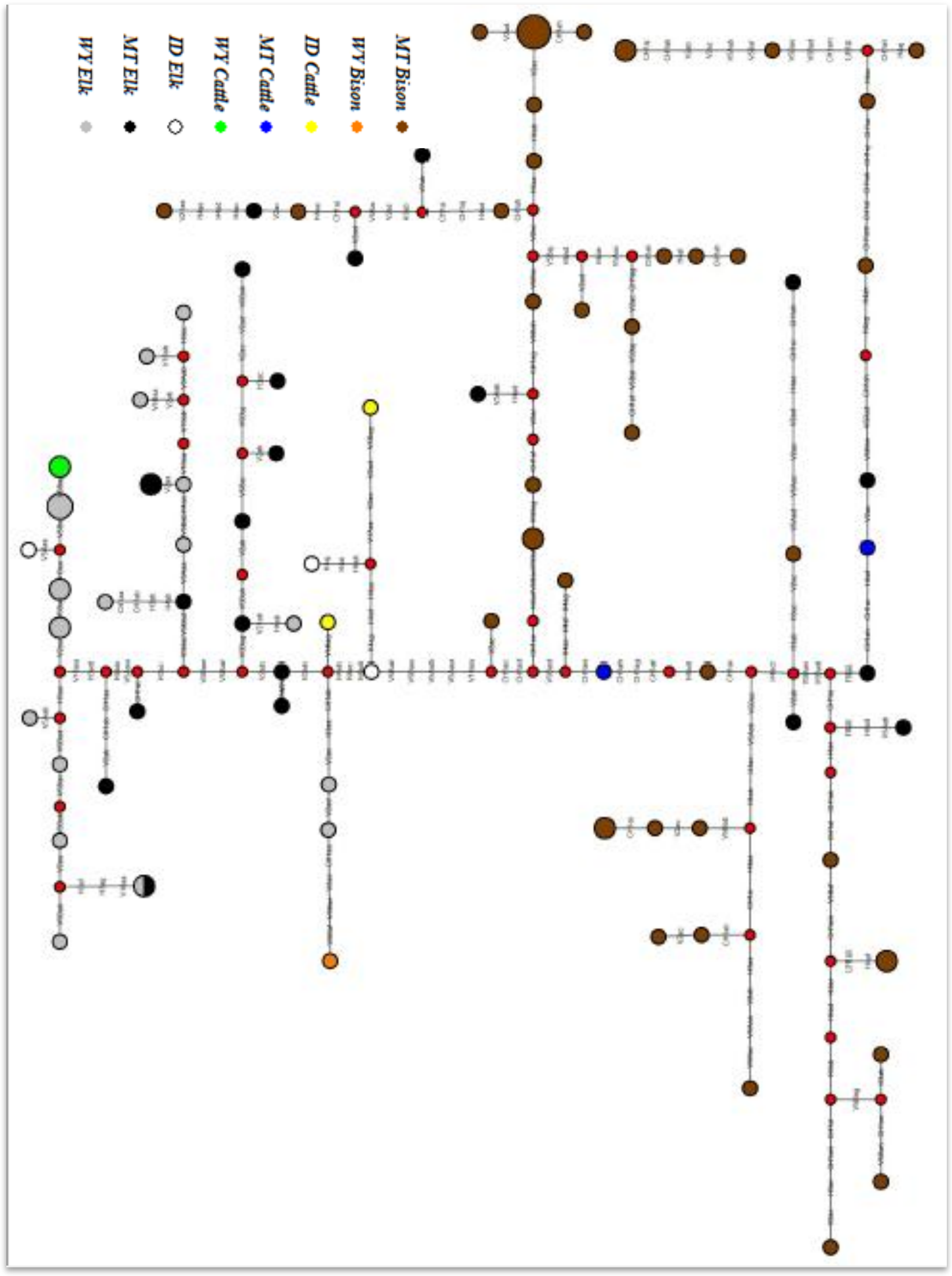


Figure 2. The haplotype network prior to conducting the pre-processing star contraction, which is used to reduce the overall complexity of the network. This haplotype network of 83 Brucella abortus haplogroups from 98 B. abortus isolates obtained from bison, cattle, and elk in the Greater Yellowstone Ecosystem (GYE). Haplotypes consist of unique multilocus genotypes from nine informative VNTR loci. The size of each filled circle (pie) is proportional to the frequency of that haplotype. Colors correspond to a host species from a given state (Montana, Wyoming or Idaho, see legend on bottom left). Each hashmark on a branch represents a minimum one mutation step assuming a stepwise mutational model (and no recombination). The patterns observed are similar to Figure 1 however, is slightly more complex due to the lack of a star contraction prior to conducting our medianjoining network analysis. The star contraction as observed above reduced the number of redundant or insignificant mutations (hash-marks on network branches) to yield 54 individual haplogroups rather than 83 haplogroups making for a more parsimonious network. 


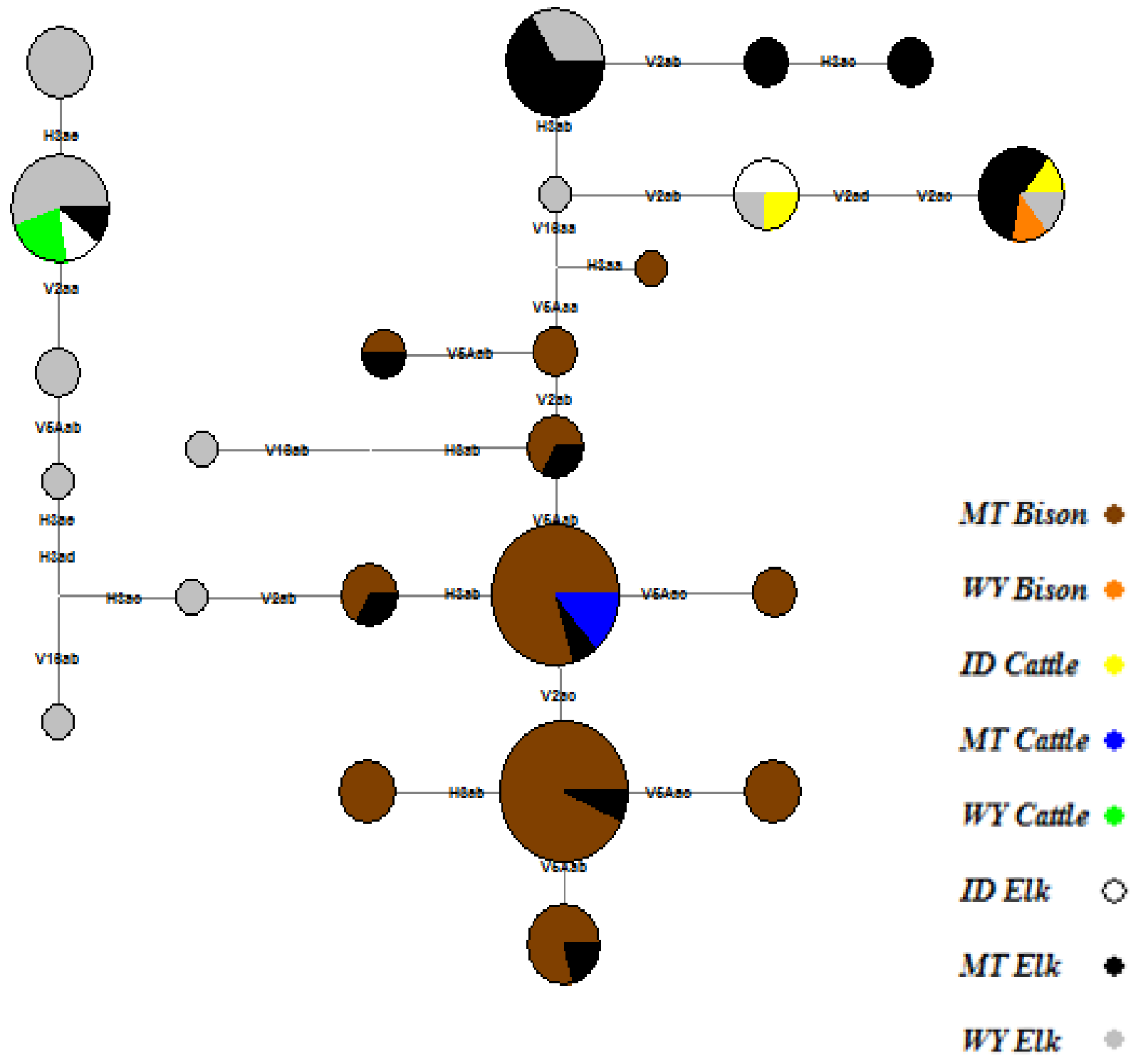

Figure 3. Haplotype network constructed when the three VNTRs with the highest number of alleles (K) and highest SDI's where removed (Table 2). The haplotype network above consists of 24 Brucella abortus haplogroups from $98 \mathrm{~B}$. abortus isolates obtained from bison, cattle, and elk in the Greater Yellowstone Ecosystem (GYE). Haplotypes consist of unique multilocus genotypes from six rather than nine informative VNTR loci. 